\title{
Endless Frontiers - When Materials and Manufacturing Come Together
}

Qing $\mathrm{HaO}^{1 *}$ and $\mathrm{Na} \mathrm{Lu}^{2 *}$

Accepted 20 October 2018

DOI: $10.30919 / \mathrm{esmm} 5 \mathrm{f} 140$

As one of the oldest research topics, manufacturing can be dated back to the beginning of the industry practice and still remains as a vibrant research field nowadays. With continuous improvements over the years, manufacturing has recently attracted enormous public attention with advanced techniques like laser sintering, ${ }^{1}$ threedimensional printing, ${ }^{2}$ electromagnetic wave processing, ${ }^{3}$ and electromagnetic interference shielding. ${ }^{4} \mathrm{New}$ ideas can also be bioinspired, such as artificial spider silks and lithium batteries grown by virus. $^{5}$

Besides new manufacturing concepts, emerging materials also introduce many unprecedented opportunities for producing new products with superior performance. In particular, numerous examples can be found with the development of nanostructured materials, including nanocomposites with high strength as structural materials, ${ }^{6,7}$ piezoelectric materials for acoustic sensing, ${ }^{8,9}$ thermoelectric materials with high power output, ${ }^{10,11}$ high-efficiency solar cells, ${ }^{12,13}$ water purification membranes, ${ }^{14,15}$ battery materials with higher capacity, ${ }^{16,17}$ and building materials for waste energy harvesting. ${ }^{18,19}$ These topics can also be related to some Grand Challenges proposed by the US National Academy of Engineering, such as "Make Solar Energy Economical" and "Provide Access to Clean Water." More examples can be added to this list and new opportunities in other fields are also anticipated.

Despite many well-established journals already in materials science, the connection between materials and manufacturing (Fig. 1) is rarely emphasized. We feel the urgency to launch a new journal to address such an important issue through a fundamental understanding of process-structure-property relation, in order to obtain unique materials behaviors through novel manufacturing processes. In addition to searching for new materials, ${ }^{20}$ the emphasis should also be on the kinetics of the chemical and physical processes involved with the manufacturing, ${ }^{21,22}$ and how to scale up such processes for mass production. ${ }^{23,24}$ Many interesting questions can be asked along this line and a few of them are listed here. For example, can we reduce the energy consumption and environmental pollution using novel materials and unconventional manufacturing processes? Can we produce conventional building and construction materials

${ }^{1}$ Department of Aerospace and Mechanical Engineering, University of Arizona, Tucson, AZ 85721, USA

${ }^{2}$ Lyles School of Civil Engineering, School of Materials Engineering, Birck Nanotechnology Center, Purdue University, West Lafayette, IN 47906, USA

*E-mail:qinghao@email.arizona.edu; luna@purdue.edu with multi-functionality that can be adaptive to the exterior environment? Can we recycle the waste heat generated during manufacturing processes? Can we better control the size and morphology of the nanostructured materials during mass production? Can we effectively recycle used batteries, solar cells, and other waste to reduce the cost of making new products? Can we better engineer the self-assembly process to make complicated three-dimensional nanostructures? The answer of these questions requires numerous interdisciplinary collaborations, which echoes the goal of $E S$ Materials \& Manufacturing: a wide range of topics covering computations to experiments for manufacturing and materials, open

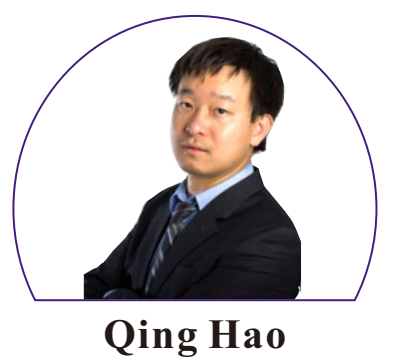

Qing Hao is an Associate Professor of Department of Aerospace and Mechanical Engineering at the University of Arizona. His research focuses on nanoscale energy transport in materials and electronic devices, including thermoelectrics, high-power electronics, and $2 D$ materials. He received the $2008 R \& D 100$ Award as a team member for thermoelectrics research, 2015 AFOSR YIP Award for graphene studies, and 2017 NSF CAREER Award for thermal studies of grain boundaries.

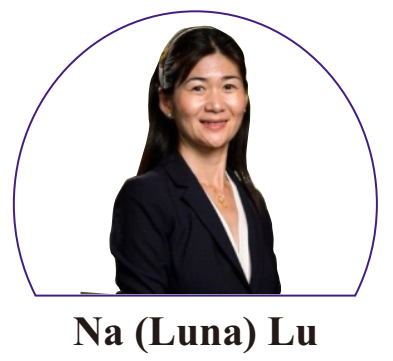

$\mathrm{Na}$ (Luna) Lu is an associate professor of the Lyles School of Civil Engineering, School of Materials Engineering and faculty-in-residence at Birck Nanotechnology Center at Purdue University. Her research focuses on functional nanomaterials synthesis and device development for energy harvesting and sensing applications, particularly, thermoelectric, piezoelectric and solar cells. Lu has authored over 80 technic publications; 1 book, 4 book chapters, 1 patent and 3 provisional patents. Dr. Lu has received several prestigious scientific awards including NSF CAREER award for thermoelectric materials study. 
access, and fast update. We sincerely hope this new journal to become a major platform for scholars to share their exciting results related to the next-generation materials and their related manufacturing studies.

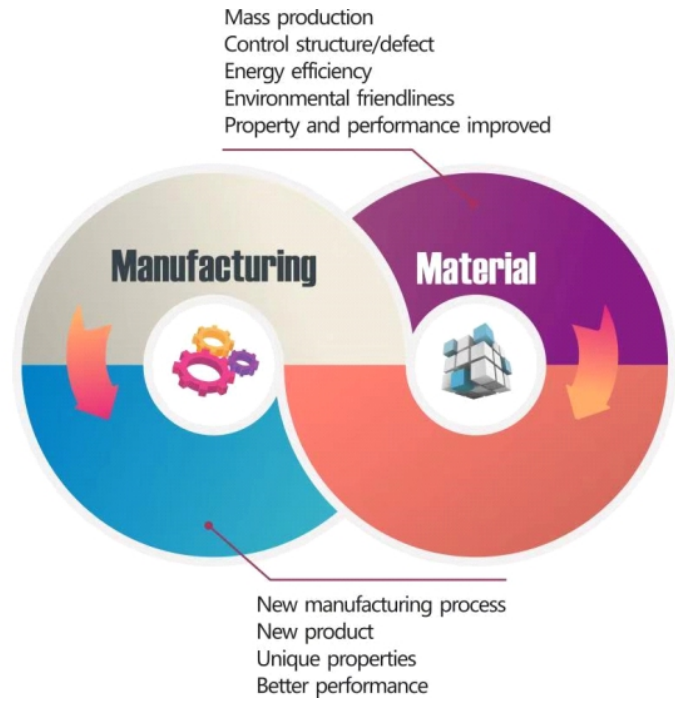

Fig. 1 The strong connection between materials and manufacturing, and the focus of ES Materials and Manufacturing

\section{References:}

1. B. Deng, R. Xu, K. Zhao, Y. Lu, S. Ganguli, G. Cheng, Mater. Today, 2018, in press, DOI: 10.1016/j.mattod.2018.03.027.

2. Y. Xiao, Z. Hong, G. Coleman, H. Zhao, R. Liang, P. Lucas, Q. Hao, ES Mater. Manuf., 2018, in press, DOI: 10.30919/esmm5f103.

3. B. Zhao, J. Deng, R. Zhang, L. Liang, B. Fan, Z. Bai, G. Shao, C. Park, Eng. Sci., 2018, 3, 5-40.

4. L. Lyu, J. Liu, H. Liu, C. Liu, Y. Lu, K. Sun, R. Fan, N. Wang, N. Lu, Z. Guo, E. Wujcik, Eng. Sci., 2018, 2, 26-42.

5. M. Moradi, Z. Li, J. Qi, W. Xing, K. Xiang, Y. Chiang, A. Belcher, Nano Lett., 2015, 15, 2917-2921.
6. N. Lu, S. Oza, Compos. B, 2013, 45, 1651-1656

7. J. Zhang, Y. Liang, X. Wang, H. Zhou, SY. Li, J. Zhang, Y. Feng, N. Lu, Q. Wang, Z. Guo, Adv. Compos. Hybrid Mater, 2018, 1, 300-309.

8. E. Ghafari, N. Lu, Compos. B, 2019, 160, 1-9.

9. E. Ghafari, Y. Yuan, W. Chen, T. Nantung, N. Lu, Cons. \& Build. Mater., 2018, 171, 504-510.

10. Y. Feng, X. Jiang, E. Ghafari, B. Kucukgok, Z. Zhang, I. Ferguson, N. Lu, Adv. Compos. \& Hybrid. Mater., 2018, 1, 114126.

11. E. Hurwitz, M. Asghar, A. Melton, B. Kucukgok, L. Su, M. Orocz, M. Jamil, L. Su, N. Lu, I. Ferguson, J. Electron. Mater. 2011, 40, 513-517.

12. N. Lu, I. Ferguson, Semi. Sci. \& Tech., 2013, 28, 074023.

13. Q. Jiang, L. Wang, C. Yuan, C. Liu, Z. Guo, N. Wang, Eng. Sci., 2018, 1, 64-68.

14. J. Huang, Y. Li, Y. Cao, F. Peng, Y. Cao, Q. Shao, H. Liu, Z. Guo, J. Mater. Chem. A., 2018, 6, 13062.

15. X. Zhang, X. Wang, X. Liu, C. Lv, Y. Wang, C. Zheng, H. Liu, C. Liu, Z. Guo, C. Shen, ACS Sustainable. Chem. Eng., 2018, 6, 10, 12580-12585.

16. W. Deng, T. Kang, H. Liu, J. Zhang, N. Wang, N. Lu, Y. Ma, A. Umar, Z. Guo, Sci. Adv. Mater., 2018, 10, 937-949.

17. X. Wang, X. Zeng, D. Cao, Eng. Sci., 2018, 1, 55-63.

18. E. Ghafari, SA. Ghahari, Y. Feng, F. Severgnini, N. Lu, Comp. Part B, 2016, 105, 160-166.

19. Y. Su, RR Kotian, N. Lu, Compos. B, 2018, 153, 124-129.

20. H. Zhao, Q. Hao, D. Xu, N. Lu, Phys. Rev. B, 2016, 93, 205206.

21. Y. Feng, A. Elquist, Y. Zhang, K. Gao, I. Feguson, A. Tzempelikos, N. Lu, Compos. B., 2019, 156, 108-112

22. B. Kucukgok, X. Wu, X. Wang, Z. Liu, I. Ferguson, N. Lu, AIP Adv., 2016, 6, 025305.

23. E. Ghafari, Y. Feng, Y. Liu, I. Ferguson, N. Lu, Compos. B, 2017, 116, 40-45.

24. C. Zhou, A. Ghods, V. Saravade, P. Patel, K. Yunghans, Y. Feng, N. Lu, I. Ferguson, ECS Trans., 2017, 77, 3-21. 